\title{
Evaluation of Biological Toxicity of CdTe Quantum Dots with Different Coating Reagents according to Protein Expression of Engineering Escherichia coli
}

\author{
Wei Xu, ${ }^{1}$ Ting Du, ${ }^{1}$ Chaoyong Xu, ${ }^{1}$ Heyou Han, ${ }^{1}$ Jiangong Liang, ${ }^{1}$ and Shaobo Xiao ${ }^{2}$ \\ ${ }^{1}$ College of Science, State Key Laboratory of Agricultural Microbiology, Huazhong Agricultural University, Wuhan 430070, China \\ ${ }^{2}$ College of Veterinary Medicine, State Key Laboratory of Agricultural Microbiology, Huazhong Agricultural University, \\ Wuhan 430070, China
}

Correspondence should be addressed to Jiangong Liang; liangjg@mail.hzau.edu.cn and Shaobo Xiao; xiaoshaobo@mail.hzau.edu.cn

Received 29 April 2015; Accepted 13 August 2015

Academic Editor: Ecaterina Andronescu

Copyright (C) 2015 Wei Xu et al. This is an open access article distributed under the Creative Commons Attribution License, which permits unrestricted use, distribution, and reproduction in any medium, provided the original work is properly cited.

\begin{abstract}
The results obtained from toxicity assessment of quantum dots (QDs) can be used to establish guidelines for the application of QDs in bioimaging. This paper focused on the design of a novel method to evaluate the toxicity of CdTe QDs using engineering Escherichia coli as a model. The toxicity of mercaptoacetic acid (MPA), glutathione (GSH), and L-cysteine (Cys) capped CdTe QDs was analyzed according to the heterologous protein expression in BL21/DE3, engineering Escherichia coli extensively used for protein expression. The results showed that the MPA-CdTe QDs had more serious toxicity than the other two kinds of CdTe QDs. The microscopic images and SEM micrographs further proved that both the proliferation and the protein expression of engineering Escherichia coli were inhibited after treatment with MPA-CdTe QDs. The proposed method is important to evaluate biological toxicity of both QDs and other nanoparticles.
\end{abstract}

\section{Introduction}

Semiconductor quantum dots (QDs) are a unique class of nanomaterials with good optical properties, such as broad excitation spectra, narrow emission spectra, high quantum yields, and good photostability $[1,2]$. Since QDs were first reported for biological applications by Alivisatos, Nie and their coworkers $[3,4]$, the use of them in bioanalysis and bioimaging has dramatically increased $[5,6]$.

QD toxicity assessment is a hot topic and the findings will help to establish useful guidelines for the use of QDs for bioimaging [7-10]. In the past decade, various methods have been proposed for the evaluation of the toxicity of QDs [11-16]. Lovrić et al. reported that unmodified CdTe QDs could induce cells to death by triggering the generation of reactive oxygen species [17]. Su et al. found that the released cadmium ions played an important role in inducing damage to HEK293 cells and that some special properties of nanoparticles contributed to the cytotoxicity of CdTe QDs at the same time [18]. Tan et al. investigated the relationship between cytotoxicity and the surface ligand of QDs and found that low cytotoxicity QDs could be designed and used as probes [19]. Ladhar et al. investigated the impact of dietary cadmium sulphide nanoparticles on zebrafish, and the results indicated that the toxicity of CdS nanoparticles was dependent on their size and concentration [16].

Up to now, several research groups have used Escherichia coli (E. coli) as a model to evaluate the toxicity of QDs and other nanoparticles [20-23]. Wang et al. studied the effects of CdTe QDs on E. coli cells, showing that CdTe QDs exhibited a dose-dependent inhibitory effect on cell growth [20]. Fang et al. investigated the effect of three different sizes of MPA-CdTe QDs on the growth of E. coli and found that CdTe QDs and their by-products had toxic effect on DNA, protein, enzyme, and so on in vivo [21]. Lai et al. investigated the inhibitory effects of different ligand-coated QDs on E. coli growth and 
found that the QDs modified with MPA showed higher toxicity than the others [15]. Xiao et al. evaluated the toxic effects of CdSe QDs and CdSe/ZnS QDs on the growth of both E. coli and Staphylococcus aureus (S. aureus) by microcalorimetry [22] and proposed that the microcalorimetric technique is a useful and more convenient tool for the quantitative analysis of the toxic effects of QDs on bacterial metabolism. The effect of QDs on E. coli cells has been widely investigated, but to our knowledge, no method has been developed based on the protein expression in engineering E. coli.

Engineering E. coli is not only a good tool for genome science but also an ideal model organism for biological research $[24,25]$. It is one of the most widely used hosts for the production of heterologous proteins [26]. The recombinant proteins expressed in engineering $E$. coli might account for up to 50 percent of the total cellular proteins [27].

In the present work, the protein expression of engineering E. coli was used to study the toxicity mechanism of CdTe QDs coated with mercaptoacetic acid (MPA), glutathione (GSH), and L-cysteine (Cys). The results showed that MPACdTe QDs exhibited more influence than the other QDs on the heterologous protein expression of engineering $E$. coli. The reason was that both the proliferation and the protein expression of engineering $E$. coli were inhibited after treatment with MPA-CdTe QDs.

\section{Experimental}

The deionized distilled water used was prepared from a Milli-Q Academic water purification system (Millipore). $\mathrm{CdCl}_{2} \cdot 2.5 \mathrm{H}_{2} \mathrm{O}, \mathrm{NaOH}, \mathrm{NaBH}_{4}, \mathrm{Na}_{2} \mathrm{TeO}_{3}$, glutaraldehyde, MPA, GSH, and Cys were purchased from Sinopharm Chemical Reagent Co., Ltd. (Shanghai, China). Isopropyl $\beta$-D-1thiogalactopyranoside (IPTG) was purchased from SigmaAldrich Co., LLC. All reagents were of analytical reagent grade and used as received.

The MPA, GSH, and Cys capped CdTe QDs were prepared according to references with some modifications [28-30]. Briefly, while synthesizing green MPA coated CdTe QDs (MPA-CdTe), cadmium chloride $(68.5 \mathrm{mg})$ was dissolved in water $(150 \mathrm{~mL})$, followed by the addition of thioglycolic acid $(30 \mu \mathrm{L})$ and $1 \mathrm{M} \mathrm{NaOH}$ solution to a final $\mathrm{pH}$ value of 11 . After that, the mixture was stirred under $\mathrm{N}_{2}$ for $20 \mathrm{~min}$, followed by the rapid addition of sodium citrate $(161.4 \mathrm{mg})$, sodium tellurite (13.2 mg), and sodium borohydride (15.0 mg) to the solution under $\mathrm{N}_{2}$ stirring. Subsequently, the reaction mixture was heated to reflux for $3 \mathrm{~h}$ under $\mathrm{N}_{2}$. Finally, the resulting QD solution was mixed with ethanol at the rate of $1: 1$ and then centrifugalized $(8000 \mathrm{rpm})$ for $5 \mathrm{~min}$. After the precipitate was resuspended in deionized water, the purified QDs were obtained. GSH and Cys capped CdTe QDs were synthesized in similar way.

The UV-Vis spectra of CdTe QDs were obtained on a Thermo Nicolet Corporation Model Evolution 300 UVVisible spectrometer. The FL spectra were acquired on a RF-5301PC (Shimadzu) fluorescence spectrometer. The TEM images of QDs were observed on a FEI Tecnai G20 transmission electron microscope.
The frozen engineering $E$. coli cells were revived in LuriaBertani (LB) medium containing ampicillin for $12 \mathrm{~h}$ at $310 \mathrm{~K}$. The engineering $E$. coli suspension obtained was transferred to a glass ampoule containing fresh LB medium and ampicillin, followed by $2 \mathrm{~h}$ incubation at $310 \mathrm{~K}$. Subsequently, the IPTG and different amounts of QDs were added into each ampoule. After $5 \mathrm{~h}$ incubation, the $E$. coli cells were collected and prepared for sodium dodecyl sulfate-polyacrylamide gel electrophoresis (SDS-PAGE) [31]. The gel images were obtained using the GelDoc 2000Fluo (Bio-Rad) gel imaging system.

The engineering E. coli cells were first fixed with $25 \%$ glutaraldehyde for $2 \mathrm{~h}$, then washed three times, and resuspended in water. After centrifugalizing (3000 rpm) for $5 \mathrm{~min}$, the precipitate was collected and dehydrated with graded ethanol series (30\%-100\%). The samples were deposited onto gold platelets as a $1 \mu \mathrm{L}$ droplet and then air-dried. A small amount of platinum was sputtered on the samples to avoid charging in the microscope.

To take the photomicrographs, bacteria of the midexponential growth phase were washed three times with sodium phosphate buffer ( $\mathrm{pH}$ 7.2) and deposited/placed onto slides as a $5 \mu \mathrm{L}$ droplet, which were immediately covered with coverslips. Photomicrographs were taken with an oil immersion microscope by IX70 (Olympus) fluorescence microscopy at magnification of 400x. The SEM images of engineering E. coli were observed on an S-570 Scanning Electron Microscope (Hitachi).

\section{Results and Discussion}

3.1. Characterization of CdTe QDs. The XRD patterns of CdTe QDs were obtained by a Bruker-D8 Advanced X-ray diffractometer. As shown in Figure S1 (see Supplementary Material available online at http://dx.doi.org/10.1155/2015/583963), the XRD patterns of Cys-CdTe QDs (Figure S1A), GSH-CdTe QDs (Figure S1B), and MPA-CdTe QDs (Figure S1C) were similar. The $2 \theta$ values of $26.3^{\circ}$ and $39.2^{\circ}$ correspond to the crystal planes (111) and (220) of cubic CdTe phase [32]. Figure 1 shows the TEM images of MPA-CdTe QDs (Figure 1(a)), GSH-CdTe QDs (Figure 1(b)), and Cys-CdTe QDs (Figure 1(c)). The sizes of MPA-CdTe QDs, GSH-CdTe QDs, and Cys-CdTe QDs were $2.7 \pm 0.2,2.5 \pm 0.2$, and $2.6 \pm$ $0.2 \mathrm{~nm}$, respectively. The concentrations of CdTe QDs were determined from the first absorption maximum of the UVVis absorption spectra (Figure 2) as reported previously by Yu et al. [33]. The peak emission wavelengths of MPA-CdTe QDs, GSH-CdTe QDs, and Cys-CdTe QDs were 560, 552, and $554 \mathrm{~nm}$, respectively.

3.2. Toxicity Assay Based on Heterologous Protein Expression of Engineering E. coli. The toxicity of CdTe QDs was evaluated according to heterologous protein expression in BL21/DE3, engineering $E$. coli extensively used for protein expression. To this end, plasmid pGEX-KG encoding glutathione S-transferase (GST) was introduced into BL21/DE3 and induced by isopropyl $\beta$-D-1-thiogalactopyranoside (IPTG) as described previously, followed by a sodium dodecyl 


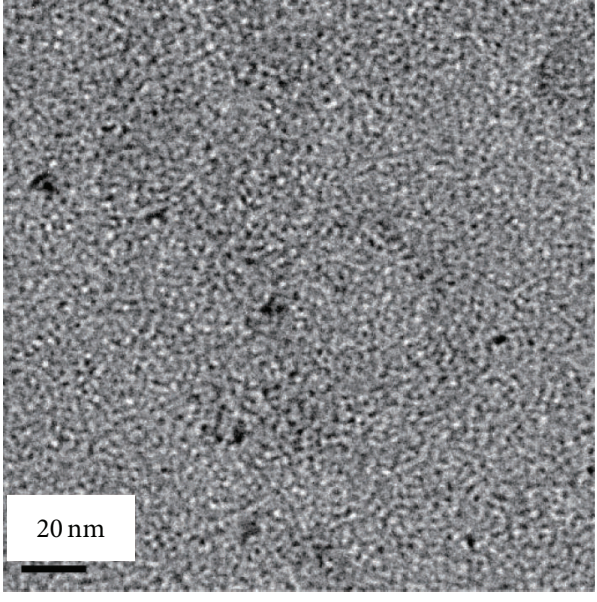

(a)

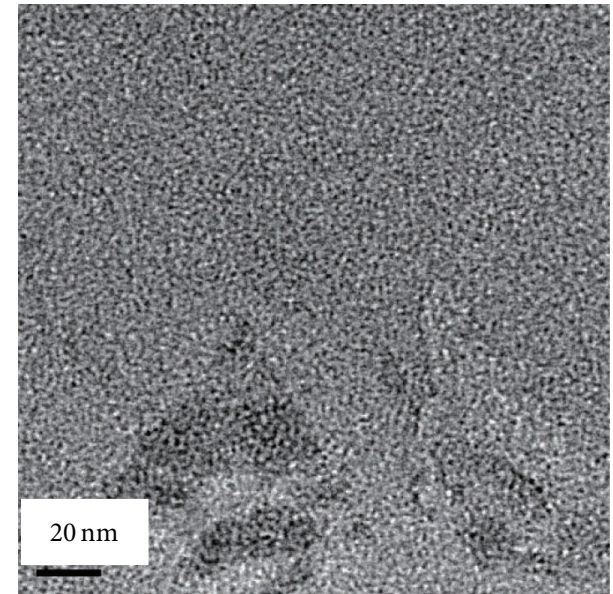

(b)

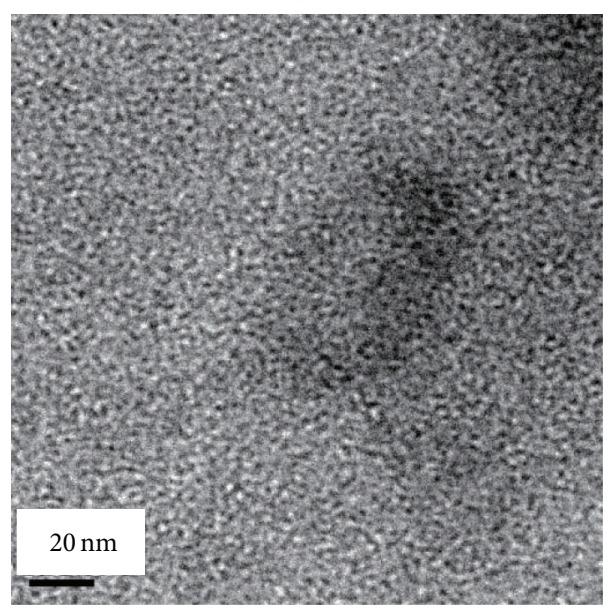

(c)

Figure 1: TEM images of MPA-CdTe QDs (a), GSH-CdTe QDs (b), and Cys-CdTe QDs (c).

sulfate-polyacrylamide gel electrophoresis (SDS-PAGE) analysis. The expression of the GST protein of E. coli cells after treatment with different concentrations of three kinds of CdTe QDs is presented in Figure 3. As shown in Figure 3(a), the expression of the GST protein significantly decreased in BL21/DE3 treated with MPA-CdTe QDs, indicating that 5 and $10 \mathrm{nM}$ MPA-CdTe QDs did not confer detectable toxicity to $E$. coli. However, when the concentration of MPA-CdTe QDs increased to $50 \mathrm{nM}$, the protein expression was strongly inhibited, suggesting that high concentration of MPA-CdTe QDs had serious toxicity. Additionally, the other protein bands become lighter due to the reduction of concentration of engineering $E$. coli. Under the same concentration conditions, the GST expression did not show a significant change after treatment with GSH-CdTe QDs (Figure 3(b)) or Cys-CdTe QDs (Figure 3(c)), even at a higher concentration. These results indicate that the surface reagents play a key role in the biological toxicity of QDs. The inhibition of the GST protein expression might be attributed to two factors: (1) CdTe QDs affect the proliferation of engineering E. coli and (2) CdTe QDs alter the physiological functions of engineering E. coli.

3.3. Toxicity Assay Based on Microscopic Images and SEM Micrographs. To further investigate the effect of CdTe QDs on engineering $E$. coli, we examined the microscopic images of engineering E. coli treated with and without CdTe QDs. As shown in Figure 4, the growing status of E. coli cells exhibited visual differences after treatment with three different CdTe QDs. The E. coli cells treated with MPA-CdTe QDs (Figure 4(b)) exhibited obviously a smaller number than those untreated with MPA-CdTe QDs, while the E. coli cells treated with GSH-CdTe QDs (Figure 4(c)) or Cys-CdTe QDs (Figure 4(d)) showed nearly the same number as the control (Figure 4(a)). The reason was due to the fact that MPA-CdTe QDs can strongly inhibit the growth of engineering E. coli., leading to the reduction of concentration of engineering $E$. coli. Lai et al. investigated the biotoxicity of CdTe QDs on Gram-negative E. coli by thermogenic curves of E. coli growth 


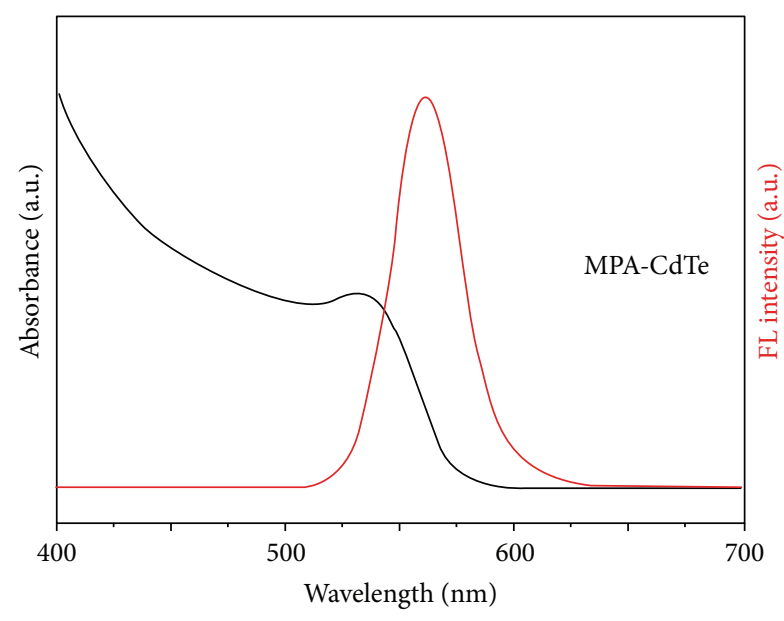

(a)

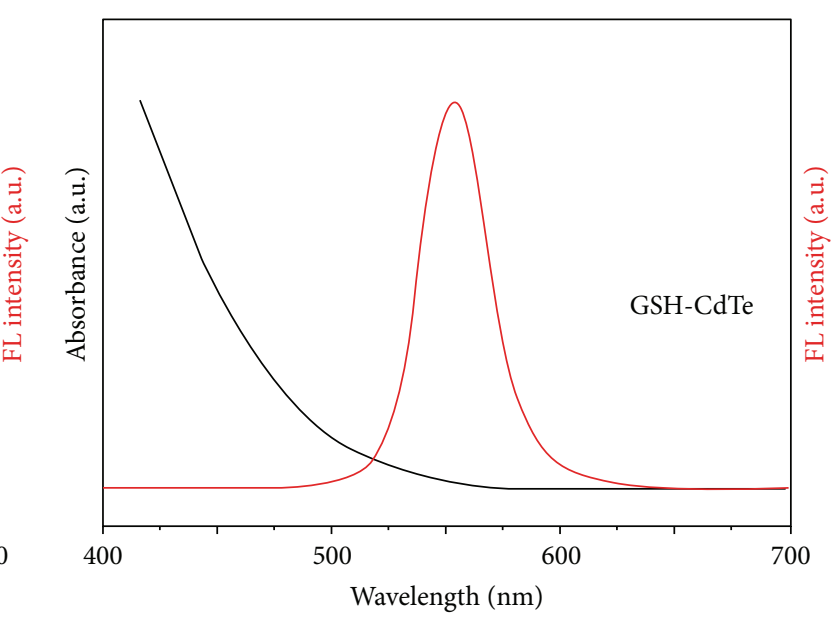

(b)

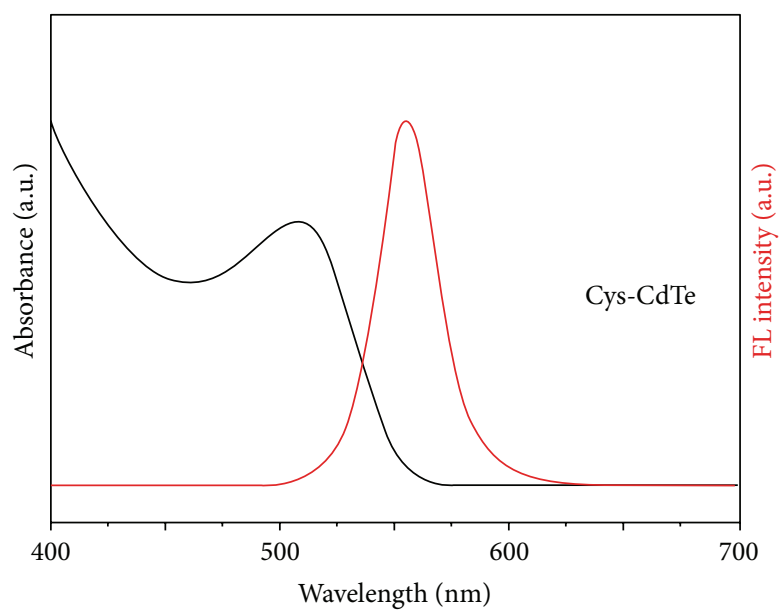

(c)

FIGURE 2: Absorption and emission spectra of three kinds of CdTe QDs. The peak emission wavelengths of MPA-CdTe QDs, GSH-CdTe QDs, and Cys-CdTe QDs were 560, 552, and $554 \mathrm{~nm}$, respectively.

[15]. They also found MPA-CdTe QDs can inhibit the growth of $E$. coli more effectively. Compared to the method of Lai and his coworkers, it is more economic and rapid to use engineering $E$. coli as sensor to evaluate the biotoxicity of QDs.

The morphologies of the majority of the cells treated with MPA-CdTe QDs were found to have changed from rod shape to stick shape (Figure 4(b)). SEM micrograph analysis further confirmed that the rod-shaped cells turned to be longer and more irregular after treatment with MPACdTe QDs (Figure 5(b)), and a large number of broken cells were present. When compared to the untreated cells (Figure 5(a)), no number change was detected in the E. coli cells treated with GSH-CdTe QDs (Figure 5(c)) or Cys-CdTe QDs (Figure 5(d)). Wang et al. also used TEM to study the effect of MPA capped CdTe QDs on E. coli cells, and the results also showed that a higher concentration of QDs would lead to a dramatic change in the morphology of cells [20]. This means MPA-CdTe has a similar effect on both normal E. coli and engineering E. coli. Therefore, it could be concluded from these results that both the proliferation and the protein expression of engineering $E$. coli were inhibited after treatment with MPA-CdTe QDs.

\section{Conclusion}

In summary, a novel method to evaluate the biological toxicity of CdTe QDs has been developed based on protein expression of engineering $E$. coli. The results indicated that the toxicity of MAA-CdTe QDs was more than that of GSHCdTe QDs and Cys-CdTe QDs on the expression of the GST protein growth in engineering $E$. coli. The proposed method can be used not only to test the interaction between QDs and bacteria but also to test the biological toxicity of other nanoparticles.

\section{Conflict of Interests}

The authors declare that there is no conflict of interests regarding the publication of this paper. 


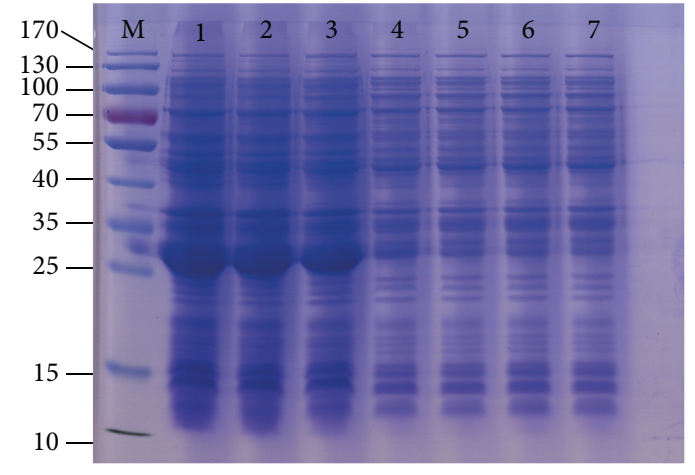

(a)

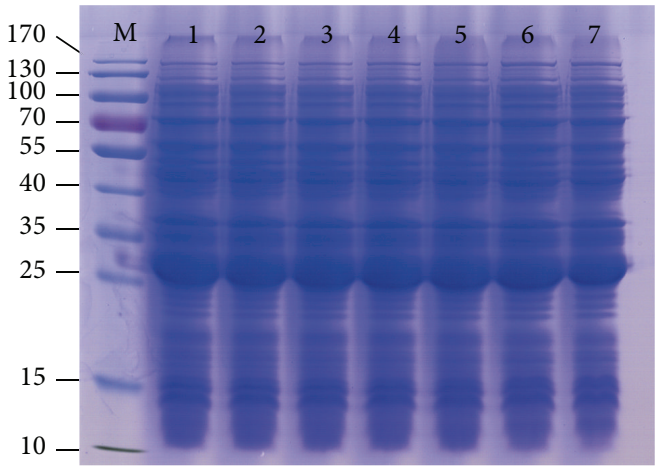

(b)

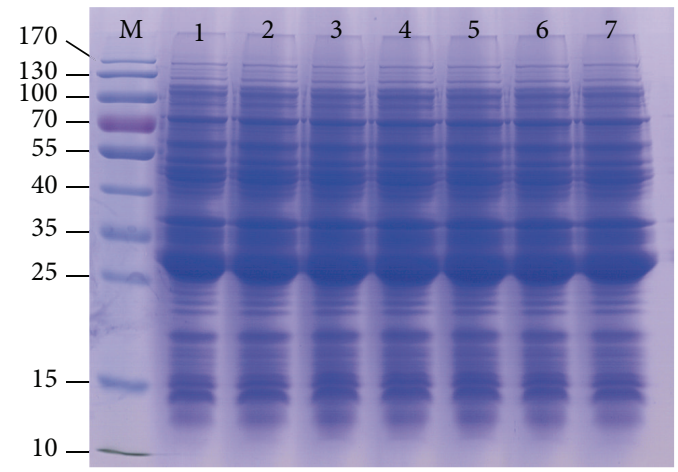

(c)

FIgURE 3: The expression of the GST protein of engineering E. coli cells after treatment with different concentrations of MPA-CdTe QDs (a), GSH-CdTe QDs (b), and Cys-CdTe QDs (c). Lane 1: the control (untreated engineering E. coli cells). Lanes 2-7: engineering E. coli cells treated with CdTe QDs at a concentration range (left to right) of 5, 10, 50, 100, 200, and $500 \mathrm{nM}$.

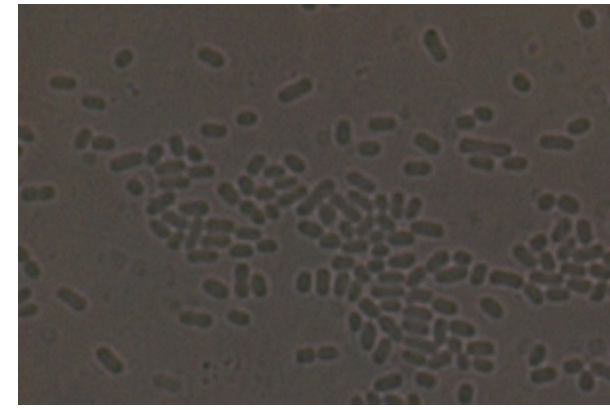

(a)

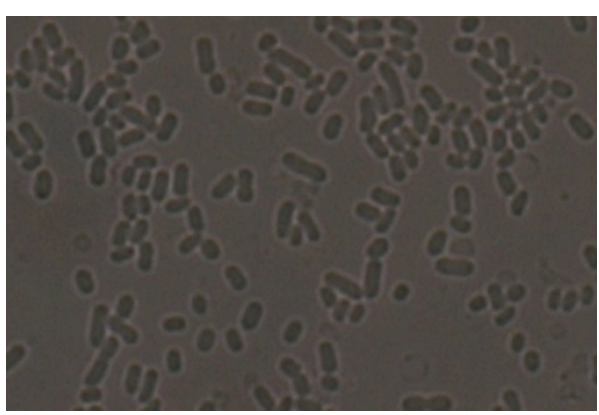

(c)

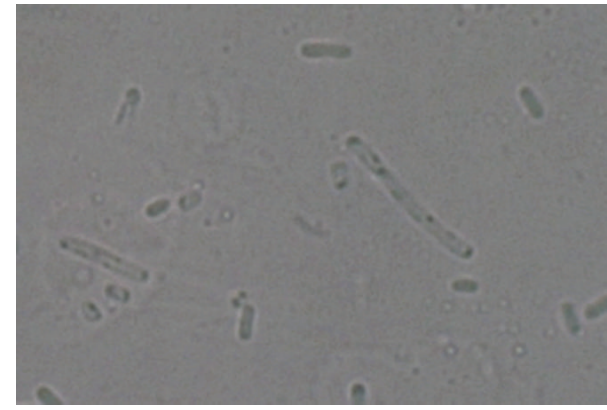

(b)

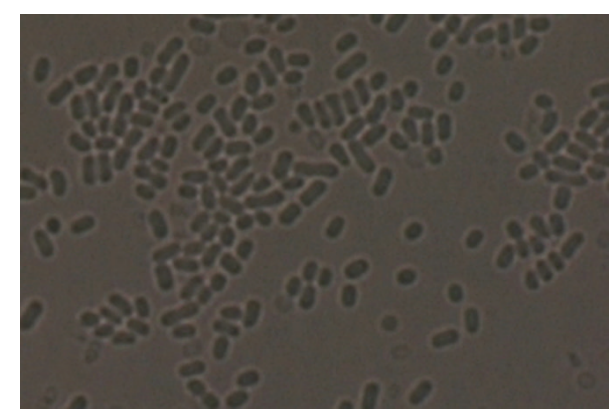

(d)

FIGURE 4: Microscopic images of engineering E. coli cells before (a) and after treatment with MPA-CdTe QDs (b), GSH-CdTe QDs (c), and Cys-CdTe QDs (d) at an identical concentration of $50 \mathrm{nM}$. 


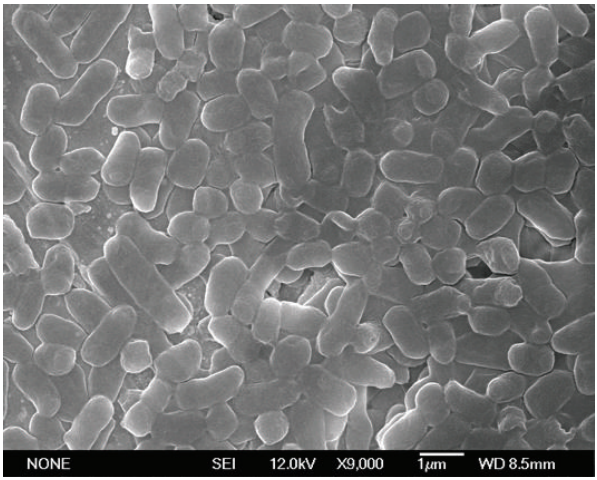

(a)

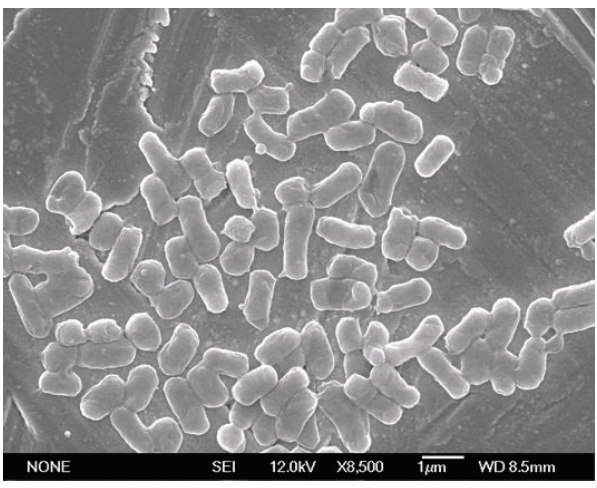

(c)

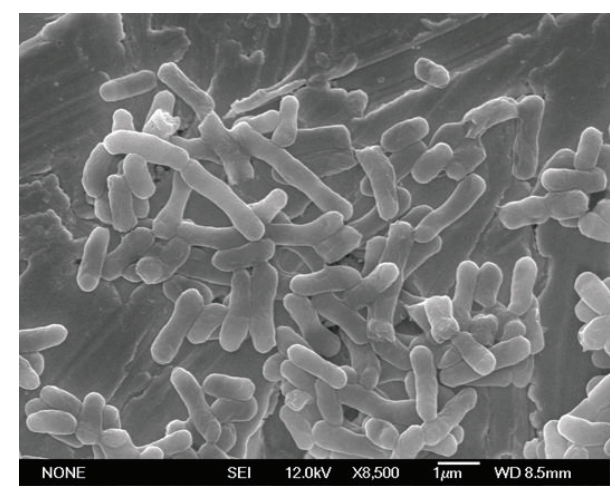

(b)

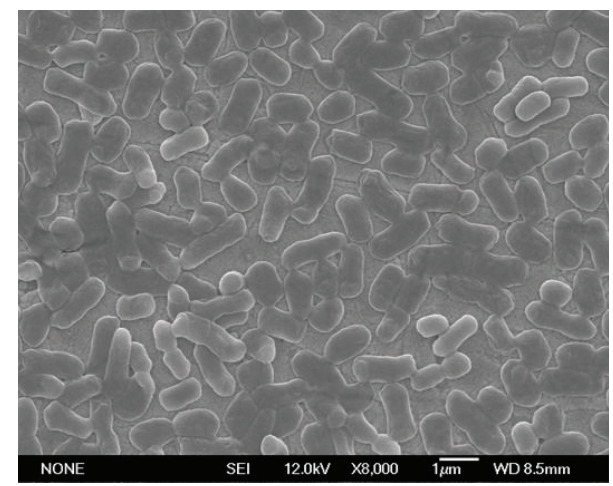

(d)

FIGURE 5: SEM micrograph of engineering E. coli cells before (a) and after treatment with MPA-CdTe QDs (b), GSH-CdTe QDs (c), and Cys-CdTe QDs (d) at an identical concentration of $50 \mathrm{nM}$. The scale bar is $1 \mu \mathrm{m}$.

\section{Acknowledgments}

The authors gratefully acknowledge the support for this research by National Nature Science Foundation of China (31372439, 31225027) and Natural Science Foundation of Hubei Province Innovation Team (2011CDA115).

\section{References}

[1] P. Zrazhevskiy, M. Sena, and X. Gao, "Designing multifunctional quantum dots for bioimaging, detection, and drug delivery," Chemical Society Reviews, vol. 39, no. 11, pp. 4326-4354, 2010.

[2] X. Michalet, F. F. Pinaud, L. A. Bentolila et al., "Quantum dots for live cells, in vivo imaging, and diagnostics," Science, vol. 307, no. 5709, pp. 538-544, 2005.

[3] M. Bruchez Jr., M. Moronne, P. Gin, S. Weiss, and A. P. Alivisatos, "Semiconductor nanocrystals as fluorescent biological labels," Science, vol. 281, no. 5385, pp. 2013-2016, 1998.

[4] W. C. W. Chan and S. Nie, "Quantum dot bioconjugates for ultrasensitive nonisotopic detection," Science, vol. 281, no. 5385, pp. 2016-2018, 1998.

[5] Y. Wang, R. Hu, G. Lin, I. Roy, and K. T. Yong, "Functionalized quantum dots for biosensing and bioimaging and concerns on toxicity," ACS Applied Materials and Interfaces, vol. 5, no. 8, pp. 2786-2799, 2013.

[6] A. Taylor, K. M. Wilson, P. Murray, D. G. Fernig, and R. Lévy, "Long-term tracking of cells using inorganic nanoparticles as contrast agents: are we there yet?" Chemical Society Reviews, vol. 41, no. 7, pp. 2707-2717, 2012.

[7] K. T. Yong, W. C. Law, R. Hu et al., "Nanotoxicity assessment of quantum dots: from cellular to primate studies," Chemical Society Reviews, vol. 42, no. 3, pp. 1236-1250, 2013.

[8] F. M. Winnik and D. Maysinger, "Quantum dot cytotoxicity and ways to reduce it," Accounts of Chemical Research, vol. 46, no. 3, pp. 672-680, 2013.

[9] X. Bellanger, P. Billard, R. Schneider, L. Balan, and C. Merlin, "Stability and toxicity of $\mathrm{ZnO}$ quantum dots: interplay between nanoparticles and bacteria," Journal of Hazardous Materials, vol. 283, pp. 110-116, 2015.

[10] R. Hardman, "A toxicologic review of quantum dots: toxicity depends on physicochemical and environmental factors," Environmental Health Perspectives, vol. 114, no. 2, pp. 165-172, 2006.

[11] K. C. Nguyen, W. G. Willmore, and A. F. Tayabali, "Cadmium telluride quantum dots cause oxidative stress leading to extrinsic and intrinsic apoptosis in hepatocellular carcinoma HepG2 cells," Toxicology, vol. 306, pp. 114-123, 2013.

[12] Y. C. Song, D. Feng, W. Shi, X. H. Li, and H. M. Ma, "Parallel comparative studies on the toxic effects of unmodified CdTe quantum dots, gold nanoparticles, and carbon nanodots on live cells as well as green gram sprouts," Talanta, vol. 116, pp. 237244, 2013.

[13] B. R. Singh, B. N. Singh, W. Khan, H. B. Singh, and A. H. Naqvi, "ROS-mediated apoptotic cell death in prostate cancer LNCaP cells induced by biosurfactant stabilized CdS quantum dots," Biomaterials, vol. 33, no. 23, pp. 5753-5767, 2012. 
[14] A. Sadaf, B. Zeshan, Z. Wang et al., "Toxicity evaluation of hydrophilic CdTe quantum dots and $\mathrm{CdTe} @ \mathrm{SiO}_{2}$ nanoparticles in mice," Journal of Nanoscience and Nanotechnology, vol. 12, no. 11, pp. 8287-8292, 2012.

[15] L. Lai, C. Lin, C. Q. Xiao et al., "Adhesion of quantum dotsinduced membrane damage of Escherichia coli," Journal of Colloid and Interface Science, vol. 389, no. 1, pp. 61-70, 2013.

[16] C. Ladhar, B. Geffroy, S. Cambier et al., "Impact of dietary cadmium sulphide nanoparticles on Danio rerio zebrafish at very low contamination pressure," Nanotoxicology, vol. 8, no. 6, pp. 676-685, 2014.

[17] J. Lovrić, S. J. Cho, F. M. Winnik, and D. Maysinger, "Unmodified cadmium telluride quantum dots induce reactive oxygen species formation leading to multiple organelle damage and cell death," Chemistry and Biology, vol. 12, no. 11, pp. 1227-1234, 2005.

[18] Y. Su, M. Hu, C. Fan et al., "The cytotoxicity of CdTe quantum dots and the relative contributions from released cadmium ions and nanoparticle properties," Biomaterials, vol. 31, no. 18, pp. 4829-4834, 2010.

[19] S. J. Tan, N. R. Jana, S. Gao, P. K. Patra, and J. Y. Ying, "Surfaceligand-dependent cellular interaction, subcellular localization, and cytotoxicity of polymer-coated quantum dots," Chemistry of Materials, vol. 22, no. 7, pp. 2239-2247, 2010.

[20] Q. Wang, T. Fang, P. Liu, X. Min, and X. Li, "Study of the bioeffects of CdTe quantum dots on Escherichia coli cells," Journal of Colloid and Interface Science, vol. 363, no. 2, pp. 476480, 2011.

[21] T. T. Fang, X. Li, Q. S. Wang, Z. J. Zhang, P. Liu, and C. C. Zhang, "Toxicity evaluation of CdTe quantum dots with different size on Escherichia coli," Toxicology in Vitro, vol. 26, no. 7, pp. 12331239, 2012.

[22] Q. Xiao, S. Huang, W. Su, P. Li, and Y. Liu, "Evaluate the potential toxicity of quantum dots on bacterial metabolism by microcalorimetry," Thermochimica Acta, vol. 552, pp. 98-105, 2013.

[23] J. S. Mcquillan and A. M. Shaw, "Whole-cell Escherichia colibased bio-sensor assay for dual zinc oxide nanoparticle toxicity mechanisms," Biosensors and Bioelectronics, vol. 51, pp. 274-279, 2014.

[24] P. Liu, W. Duan, Q. Wang, and X. Li, "The damage of outer membrane of Escherichia coli in the presence of $\mathrm{TiO}_{2}$ combined with UV light," Colloids and Surfaces B: Biointerfaces, vol. 78, no. 2, pp. 171-176, 2010.

[25] V. A. Nadtochenko, A. G. Rincon, S. E. Stanca, and J. Kiwi, "Dynamics of E. coli membrane cell peroxidation during $\mathrm{TiO}_{2}$ photocatalysis studied by ATR-FTIR spectroscopy and AFM microscopy," Journal of Photochemistry and Photobiology A: Chemistry, vol. 169, no. 2, pp. 131-137, 2005.

[26] F. Baneyx, "Recombinant protein expression in Escherichia coli," Current Opinion in Biotechnology, vol. 10, no. 5, pp. 411-421, 1999.

[27] D. M. Francis and R. Page, "Strategies to optimize protein expression in E. coli," in Current Protocols in Protein Science, chapter 5, unit 5.24, pp. 21-29, John Wiley \& Sons, 2010.

[28] Z. Sheng, H. Han, and J. Liang, "The behaviors of metal ions in the CdTe quantum dots- $\mathrm{H}_{2} \mathrm{O}_{2}$ chemiluminescence reaction and its sensing application," Luminescence, vol. 24, no. 5, pp. 271-275, 2009.

[29] Y. Zheng, S. Gao, and J. Y. Ying, "Synthesis and cellimaging applications of glutathione-capped CdTe quantum dots," Advanced Materials, vol. 19, no. 3, pp. 376-380, 2007.
[30] H. Bao, E. Wang, and S. Dong, "One-pot synthesis of CdTe nanocrystals and shape control of luminescent CdTe-cystine nanocomposites," Small, vol. 2, no. 4, pp. 476-480, 2006.

[31] J. Brosius, M. Erfle, and J. Storella, "Spacing of the -10 and -35 regions in the tac promoter. Effect on its in vivo activity," The Journal of Biological Chemistry, vol. 260, no. 6, pp. 3539-3541, 1985.

[32] Z. Xiao, D. Liu, Z. Tang, H. Li, and M. Yuan, "Synthesis and characterization of poly(lactic acid)-conjugated CdTe quantum dots," Materials Letters, vol. 148, pp. 126-129, 2015.

[33] W. W. Yu, L. H. Qu, W. Z. Guo, and X. G. Peng, "Experimental determination of the extinction coefficient of CdTe, CdSe, and CdS nanocrystals," Chemistry of Materials, vol. 15, no. 14, pp. 2854-2860, 2003. 

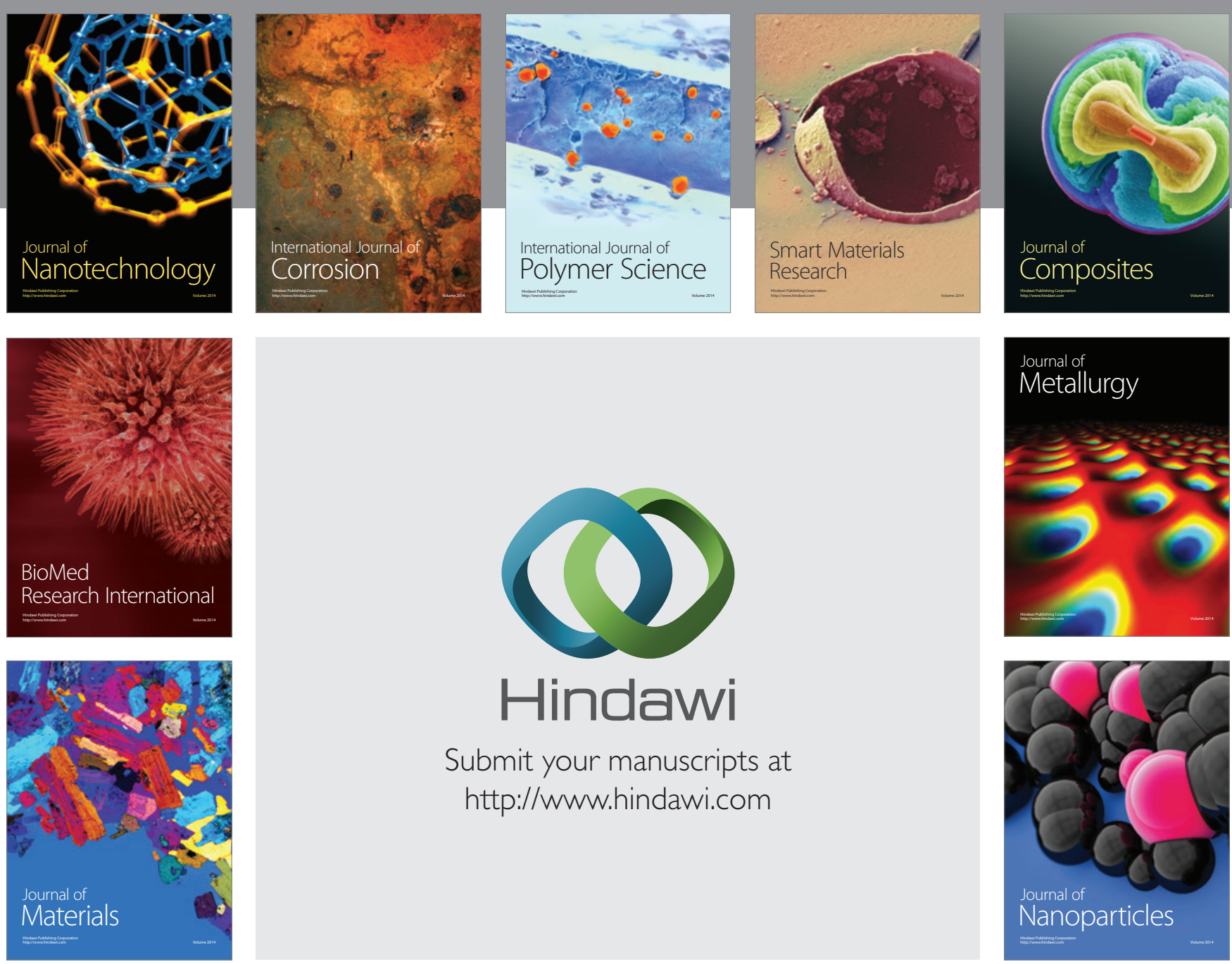

Submit your manuscripts at http://www.hindawi.com
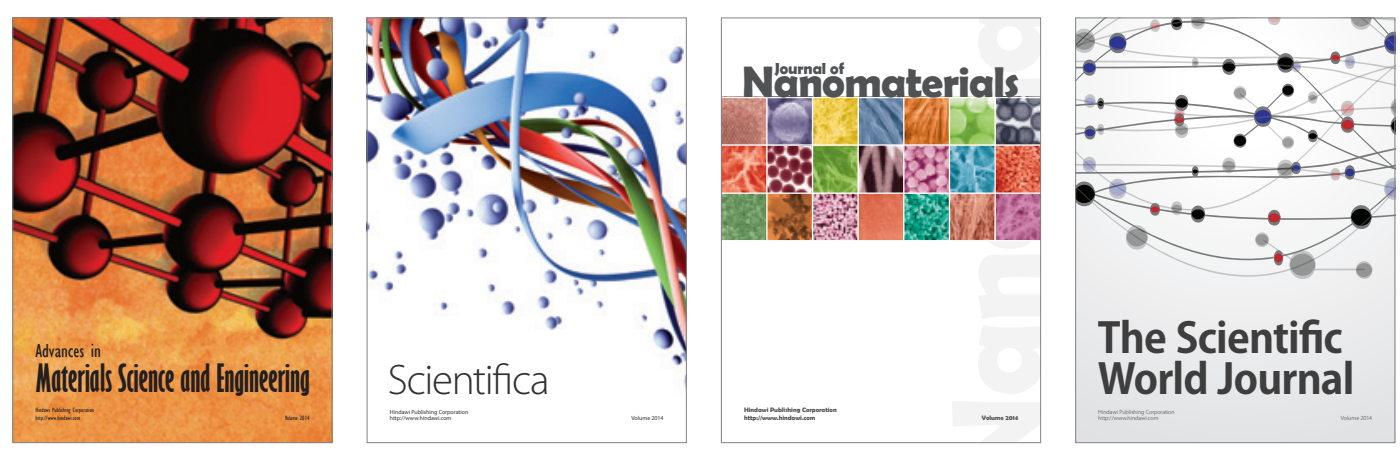

\section{The Scientific World Journal}
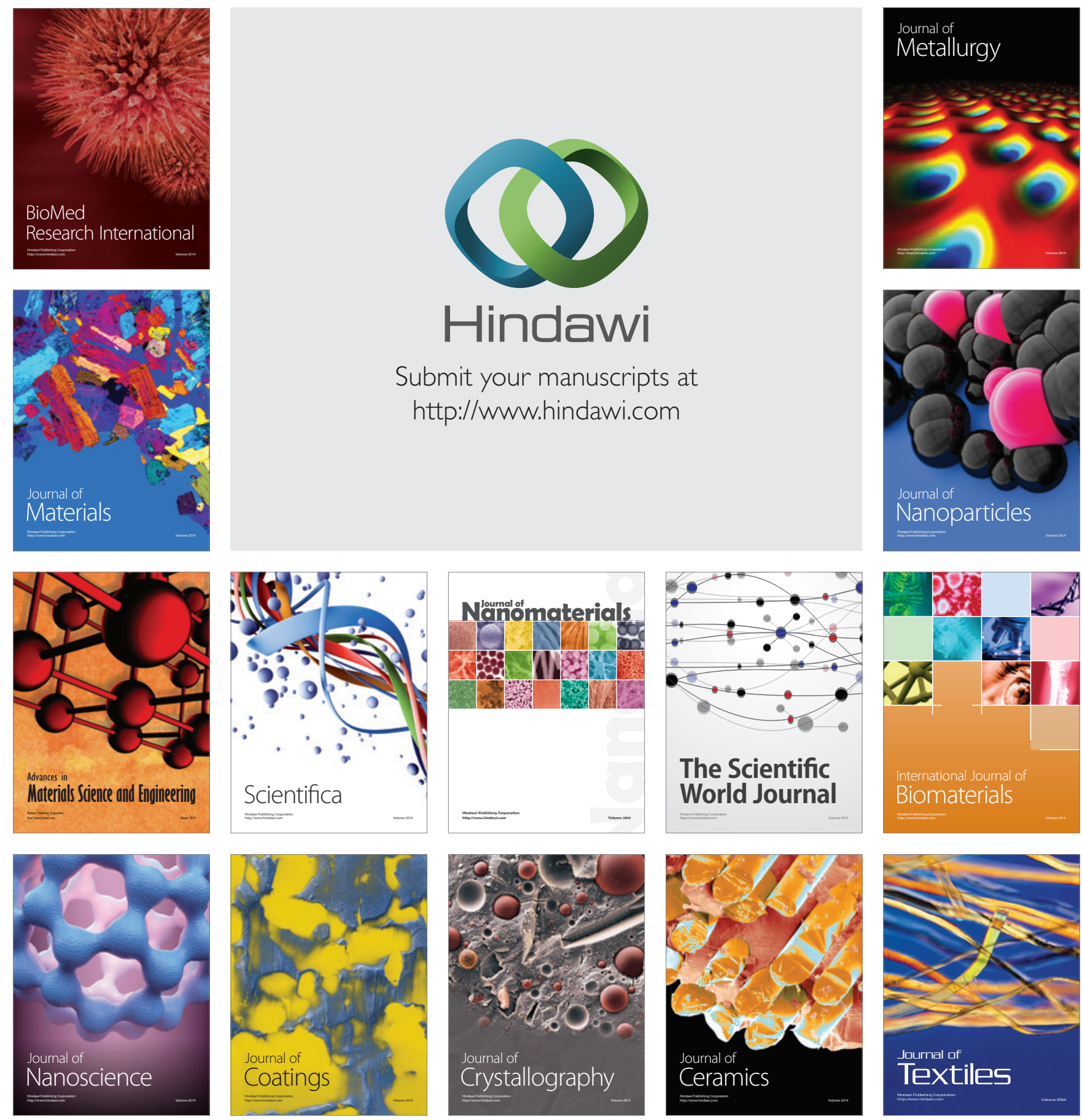